\title{
Correction to: Simultaneous detection of four lily-infecting viruses by a multiplex RT-PCR assay
}

\author{
Mi Sang $\mathrm{Lim}^{1} \cdot$ Dong Joo Min ${ }^{2}$ Jin Sung Hong ${ }^{2}$ Sun Hee Choi ${ }^{1}$ (I)
}

Published online: 19 April 2021

(c) The Phytopathological Society of Japan and Springer Japan KK, part of Springer Nature 2021

\section{Correction to: Journal of General Plant Pathology https://doi.org/10.1007/s10327-021-00992-0}

In the original publication of the article, the supplementary file 1 was wrongly updated. The correct supplementary file 1 is given in this correction.

The original article has been corrected.

Supplementary Information The online version contains supplementary material available at https://doi.org/10.1007/s10327-021-01008-7.

Publisher's Note Springer Nature remains neutral with regard to jurisdictional claims in published maps and institutional affiliations.

The original article can be found online at https://doi.org/10.1007/ s10327-021-00992-0.

Sun Hee Choi

paxs@swu.ac.kr

1 Department of Horticulture, Biotechnology and Landscape Architecture, Seoul Women's University, 621 Hwarangro, Nowon, Seoul 01797, Korea

2 Interdisciplinary Program in Smart Agriculture, Kangwon National University, Chuncheon 24341, Korea 